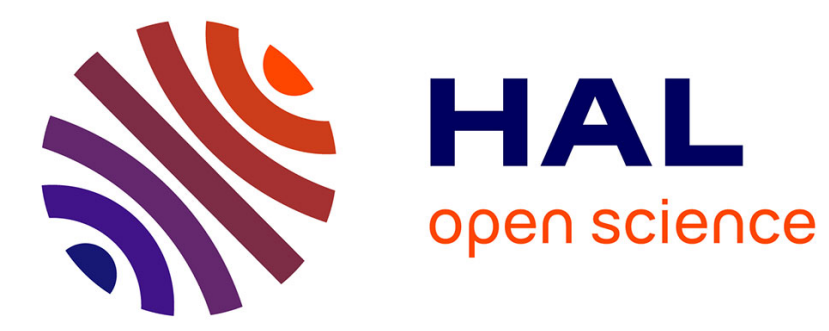

\title{
Microscopic observations of samples affected by the delayed ettringite formation (DEF)
}

\author{
Ali-Nordine Leklou, Jean-Emmanuel Aubert, Gilles Escadeillas
}

\section{To cite this version:}

Ali-Nordine Leklou, Jean-Emmanuel Aubert, Gilles Escadeillas. Microscopic observations of samples affected by the delayed ettringite formation (DEF). Materials and structures, 2008, 42, pp.1369-1378. 10.1617/s11527-008-9456-9 . hal-01007045

\section{HAL Id: hal-01007045 \\ https://hal.science/hal-01007045}

Submitted on 16 Oct 2018

HAL is a multi-disciplinary open access archive for the deposit and dissemination of scientific research documents, whether they are published or not. The documents may come from teaching and research institutions in France or abroad, or from public or private research centers.
L'archive ouverte pluridisciplinaire $\mathbf{H A L}$, est destinée au dépôt et à la diffusion de documents scientifiques de niveau recherche, publiés ou non, émanant des établissements d'enseignement et de recherche français ou étrangers, des laboratoires publics ou privés. 


\title{
Microscopic observations of samples affected by delayed ettringite formation (DEF)
}

\author{
Nordine Leklou · Jean-Emmanuel Aubert · Gilles Escadeillas
}

\begin{abstract}
This article, which deals with the study of the microscopic modifications of DEF-affected materials, has two main objectives. The first one is to study the influence of sample preparation on the microcracks of specimens observed in Scanning Electron Microscopy (SEM). From the results of this study, it can be concluded that direct observations of the samples are inappropriate because they produce cracks that are not ascribable to the pathology. It is therefore preferable to use an indirect technique of observation such as the replica technique. This technique was developed in the 1980 s and used to study the evolution of microcracking due to mechanical damage to the concrete. The results presented in this article show that it is possible to use this technique to study the microcracking associated with delayed ettringite formation. The second objective is to study ettringite formation during the swelling of DEF-affected specimens. The main results show that secondary ettringite is initially formed in the pasteaggregate interface even at low levels of expansion. For these levels of expansion, there is no trace of secondary ettringite or microcracks observable in the
\end{abstract}

N. Leklou · J.-E. Aubert $(\bowtie) \cdot$ G. Escadeillas LMDC (Laboratoire Matériaux et Durabilité des Constructions), Université de Toulouse, UPS, INSA, 135, avenue de Rangueil, 31077 Toulouse, France e-mail: aubert@insa-toulouse.fr paste. However, for higher expansions, cracks filled with ettringite appear in the paste.

Résumé Cet article, qui porte sur le suivi des modifications à l'échelle microscopique de matériaux atteints de DEF, a deux objectifs principaux. Le premier concerne l'étude de l'influence de la préparation des échantillons sur la microfissuration des éprouvettes observées au Microscope Electonique à Balayage (MEB). Les résultats de cette étude permettent de conclure que les observations directes des échantillons ne sont pas adaptées car elles produisent des fissures qui ne sont pas imputables à la pathologie. Ainsi, il est préférable d'utiliser une technique indirecte d'observation comme la technique de la réplique. Cette technique a été développée et utilisée il y a longtemps pour étudier l'évolution de la microfissuration provoquée par un endommagement mécanique du béton. Les résultats présentés dans ce papier montrent qu'il est possible d'utiliser cette technique pour l'étude de la microfissuration associée à la formation d'ettringite différée. Le second objectif de cette étude concerne le suivi de la formation de l'ettringite au cours du gonflement des éprouvettes. Les principaux résultats montrent que l'ettringite secondaire se forme d'abord à l'interface pâte-granulat même pour des niveaux d'expansion très faibles. Pour ces niveaux d'expansion, il n'y a pas de trace d'ettringite secondaire ou de microfissures observables dans la pâte. Par contre, pour des expansions plus importantes, des fissures pleines d'ettringite apparaissent dans la pâte. 
Keywords Delayed ettringite formation .

Expansion - Microcracks · Scanning electron microscopy

\section{Introduction}

Heat-induced internal sulphate attack [still commonly referred to as delayed ettringite formation (DEF)] is a chemical reaction observed in hardened cement mortars and concrete exposed to excessive temperatures at early ages. The result of this pathology is an expansion due to the delayed ettringite formation without an external source of sulphate [1,2]. The reaction mechanism of DEF involves a large number of parameters, the importance of which is not always well understood [2-8]. According to the literature, the most influential parameters are the temperature [a high temperature $\left(>70^{\circ} \mathrm{C}\right)$ inhibits the formation of non-expansive preliminary ettringite], the sulphate content of the cement and the presence of water. Other factors are also quoted, such as the preliminary cracking of the samples [8-11] and the alkali content of the cement $[4,8,12,13]$.

Many years of research on the subject have increased the knowledge of this pathology and, in particular, the influence of the various parameters. The main conclusions of this research were summarized at the RILEM workshop on Internal Sulfate Attack and Delayed Ettringite Formation [14]. However, some controversy still remains, e.g. about the explanation of the mechanisms involved in the expansion [7]. Two theories continue to oppose all researchers working on this topic. The first theory suggests that late nucleation and growth of ettringite in cracks and at the paste-aggregate interface is the cause of the expansion of specimens [7, 15]. Contrary to this first theory, the second one argues that the expansive pressure responsible for DEF is developed within the paste matrix, resulting in paste expansion that in turn causes microcracks to occur at the pasteaggregate interface and within the paste [2, 16, 17]. Then, the ettringite recrystallizes in the new porosity formed without causing additional expansion.

Investigation by Scanning Electron Microscopy (SEM) has been carried out on this subject [18] but there are still some doubts about the microcracks observed. The majority of authors conclude that it is difficult to know whether the microcracking observed on the microscopic images is directly ascribable to the DEF or if it formed during the preparation of the samples and their observation using the SEM (in particular because of the high-vacuum in the SEM). Moreover, many SEM observations concern specimens for which the sulphate reaction has already occurred. Little research has made microscopic observations of evolution during the expansion (in particular in terms of microcracks) and the majority of work has focused on monitoring the evolution of the chemical composition of the cement paste by X-ray microanalyses [6, 16, 19].

The study presented in this article had two main objectives. First, the effects of the technique of SEM observation on the microcracking of DEF-affected samples was studied. Three observation procedures were used, including the replica technique, in order to verify whether the analysis procedure created additional microcracks or not. The replica technique was developed in the 1980s and used to study the evolution of microcracking due to mechanical damage to the concrete. One of the original ideas of the work presented in this article is the use of this technique to study the microcracking associated with delayed ettringite formation. Secondly, the study looked into the relationship between the evolution of the expansions measured on a macroscopic scale and changes in the material at microscopic scale. As the first signs of this pathology sometimes take a very long time (several years) to appear, a part of the study was carried out on a mortar doped with sodium sulphate. This made it possible to accelerate and expand the phenomena and thus facilitate their study in the laboratory. However, to allow the conclusions of this work to be exploited in the case of real materials, the results obtained on the mortar with sodium sulphate were confirmed by a study carried out on a traditional concrete conserved in the laboratory for more than 3 years under favourable conditions.

\section{Experiments}

\subsection{Materials}

Two cements were used in this study. Both were Ordinary Portland Cement (CEM I 52,5 R type according to the NF EN 197-1 standard), comparable to the ASTM Type III cement which is, according to 
the literature, the cement the most susceptible to DEF [20-22].

The chemical analyses of these two cements are given in Table 1 along with the phase compositions from Bogue calculations. To accelerate and amplify the appearance of the phenomenon, 3.1\% (by weight of cement) of sodium sulphate $\left(\mathrm{Na}_{2} \mathrm{SO}_{4}\right)$ was added to the mortar [8]. The sodium sulphate used was a pure commercial product and its fineness was also comparable to that of the cement. Two kinds of French siliceous aggregates were used: siliceous aggregates from the Palvadeau sand quarry and standard sand from Leucate. Both aggregates are classified as non-reactive with respect to the alkalisilica reaction by NF-P 18-590. Aggregate of a siliceous nature was chosen because the expansion is faster than that with limestone aggregate [23-25].

Two types of materials were studied: "mortar A" containing sodium sulphate and cement $\mathrm{A}$, and "concrete B" prepared using cement B. The mortar (3:1:0.5 sand: cement: water) was prepared according to standard NF EN 196-1. The prisms of mortar were cast in metallic moulds of $40 \times 40 \times 160 \mathrm{~mm}$. The concrete was optimized with respect to slump for the mix design having a W/C ratio of 0.48 . The mix design of concrete ' $\mathrm{B}$ ' is given in Table 2 .

Concrete samples were cast in $70 \times 70 \times 280 \mathrm{~mm}$ metallic moulds. The mortar and concrete samples were cured directly in their moulds equipped with

Table 1 Chemical and mineralogical composition of the cements $(\% \mathrm{w} / \mathrm{w})$

\begin{tabular}{lcc}
\hline Cement & "A" & " \\
& Content $(\%)$ & Content $(\%)$ \\
\hline $\mathrm{SiO}_{2}$ & 19.7 & 19.1 \\
$\mathrm{Al}_{2} \mathrm{O}_{3}$ & 5.2 & 3.8 \\
$\mathrm{Fe}_{2} \mathrm{O}_{3}$ & 2.4 & 3.1 \\
$\mathrm{CaO}$ & 63.7 & 60.6 \\
$\mathrm{MgO}$ & 2.7 & 1.7 \\
$\mathrm{SO}_{3}$ & 3.2 & 3.1 \\
$\mathrm{~K}_{2} \mathrm{O}$ & 0.7 & 1.1 \\
$\mathrm{Na}_{2} \mathrm{O}$ & 0.2 & 0.5 \\
$\mathrm{Equivalent}_{\mathrm{Na}} \mathrm{O}$ & 0.7 & 1.2 \\
$\mathrm{C}_{3} \mathrm{~S}$ Bogue & 60.0 & 53.1 \\
$\mathrm{C}_{2} \mathrm{~S}$ Bogue & 9.1 & 15.3 \\
$\mathrm{C}_{3} \mathrm{~A}$ Bogue & 9.7 & 6.9 \\
$\mathrm{C}_{4} \mathrm{AF}$ Bogue & 7.3 & 9.3 \\
\hline
\end{tabular}

Table 2 Mix design of concrete $\mathrm{B}$, unit $\mathrm{kg} / \mathrm{m}^{3}$

\begin{tabular}{lc}
\hline Material & Content \\
\hline Cement B & 424 \\
Water & 201 \\
Gravel & 1,102 \\
$\quad(4 / 12.5 \mathrm{~mm})$ & \\
Sand $(0 / 4 \mathrm{~mm})$ & 669 \\
W/C & 0.48 \\
\hline
\end{tabular}

embedded length measurement studs. During the thermal treatment, the moulds were covered with a metallic plate to prevent evaporation.

\subsection{Procedures}

\subsubsection{Heat treatment}

After casting, the mortar and concrete specimens were cured according to the heat treatment presented in Fig. 1. This heat treatment is representative of the treatments used in some precast industries. The treatment (called "theoretical cycle" in Fig. 1) follows a cycle divided into four phases:

- Phase No. 1: pre-cure at $20^{\circ} \mathrm{C}$ for $1 \mathrm{~h}$.

- Phase No. 2: temperature rise: at $20^{\circ} \mathrm{C} / \mathrm{h}$ for $3 \mathrm{~h}$.

- Phase No. 3: temperature plateau $80^{\circ} \mathrm{C}$ for $10 \mathrm{~h}$.

- Phase No. 4: natural return to ambient temperature of $20^{\circ} \mathrm{C}$ over $11 \mathrm{~h}$.

The moulds, covered with a metallic plate to prevent evaporation during the heat treatment, were placed in a drying oven equipped with a temperature controller. Thermocouples were placed in the control specimen to verify the temperatures reached during the treatment (curve called "experimental temperature cycle" in Fig. 1). After cooling, the prisms were

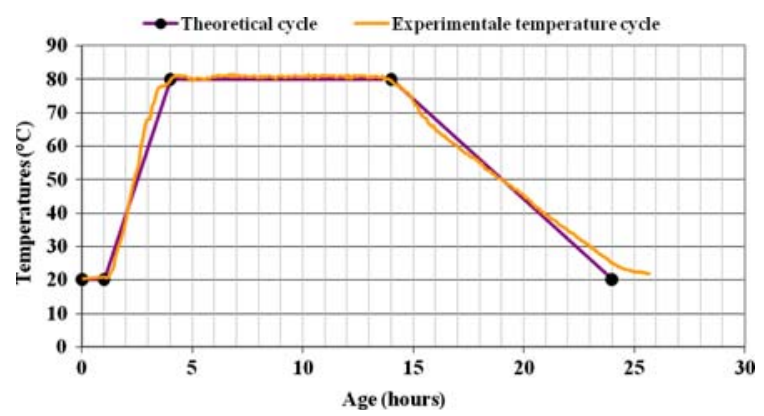

Fig. 1 Temperature cycle imposed on the heat-cured specimens 
demoulded and stored in water at $20^{\circ} \mathrm{C}$. In both cases, the storage water was not changed during the tests.

\subsubsection{Test procedure}

Expansion measurements were performed with an extensometer having an accuracy of $1 \mu \mathrm{m}$ (mortar $6 \mu \mathrm{m} / \mathrm{cm}$ and concrete $4 \mu \mathrm{m} / \mathrm{cm}$ ). The frequency of these measurements was high (weekly) during the period of maximum expansion speed and decreased (to monthly) when the expansion speed was low. Each point on the graph is derived from the average calculated on the expansion of three specimens.

For scanning electron microscopy (SEM) observations, a JEOL $6380 \mathrm{LV}$ equipped with a backscattered electron (BSE) detector was used. The microscopic examinations were carried out using three different procedures on the same polished sections of concrete or mortar specimens to allow comparisons between the observations:

- first, replicas of the observed sections were prepared just after the polishing of the samples (no desiccation allowed),

- then direct observations were made using the SEM in low-vacuum (LV) mode (no metallization necessary, pressure of $60 \mathrm{~Pa}$ in the SEM),

- and finally, the specimens were coated with a carbon deposit for observations using the SEM in high-vacuum (HV) mode.

The single replica technique has already been used for the visualization of microcracks by Ollivier [26]. The methyl acetate was pulverized on the surface of the sample and a film of bioden (celluloseacetyl) was immediately applied to the polished surface. Once the solvent had evaporated (2 $\mathrm{min}$ ), the film was delicately removed and pasted on a brass support. The metallized replica was then observed with an SEM. This technique has the advantage of not introducing artefacts in the observation of microcracks [27].

\section{Results}

\subsection{Mortar A}

Figure 2 presents the length variations of mortar A. Mortar A swelled quickly and the plot has a sigmoid form as observed by Brunetaud et al. [28].

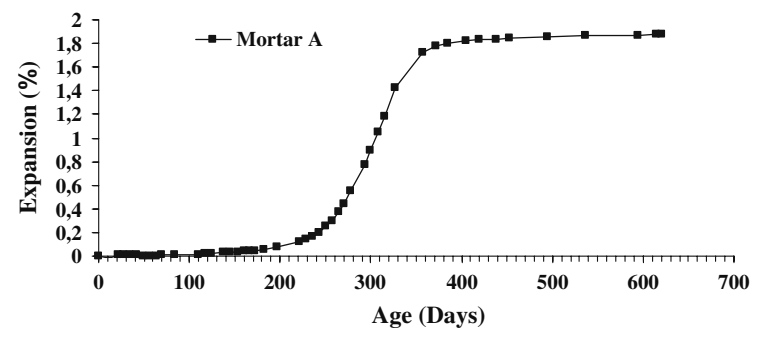

Fig. 2 Length variations of mortar A

The curve shows a marked acceleration at $0.1 \%$ of expansion. The ultimate value of expansion is high $(1.8 \%)$, which is not surprising considering the composition of the mortar (with $3.1 \%$ of sodium sulphate).

Figure 3 shows SEM images of the same polished section of mortar A using three observation techniques (replicas, low-vacuum and high-vacuum) at 200 days, i.e. at the beginning of the expansion acceleration.

The BSE images in low-vacuum mode and highvacuum mode are similar and quite comparable to conventional images of DEF-affected specimens [18]. Delayed ettringite bands are observed at the pasteaggregate interface and some empty cracks are present in the paste (highlighted by circles in Fig. 3a, b). The SEI of the corresponding replica is a little less clean than the direct observations but it is possible to recognize the delayed ettringite bands in Fig. 3c, on the surface of the left large aggregate (the replica images are inverted because of the technique used). However, it is very clear on the microscopic image of the replica (Fig. 3c) that there is no crack in the paste and particularly in places where there were empty cracks in the direct observation (low- or high-vacuum mode).

Figure 4 shows BSE images of mortar $\mathrm{A}$ at different stages of expansion:

- at the beginning of swelling when expansions are still insignificant (145 days),

- when the speed of expansion begins to accelerate (200 days),

- at the end of swelling when expansion has reached a plateau (450 days).

The image of the 145-day-old specimens (Fig. 4a) represents the trace left by an aggregate in which delayed ettringite was found. For this amplitude of 
Fig. 3 BSE of mortar A in low- and high-vacuum mode $(\mathbf{a}, \mathbf{b})$ and SEI of the $600 \times)$ replica $(\mathbf{c}),(200$ days,
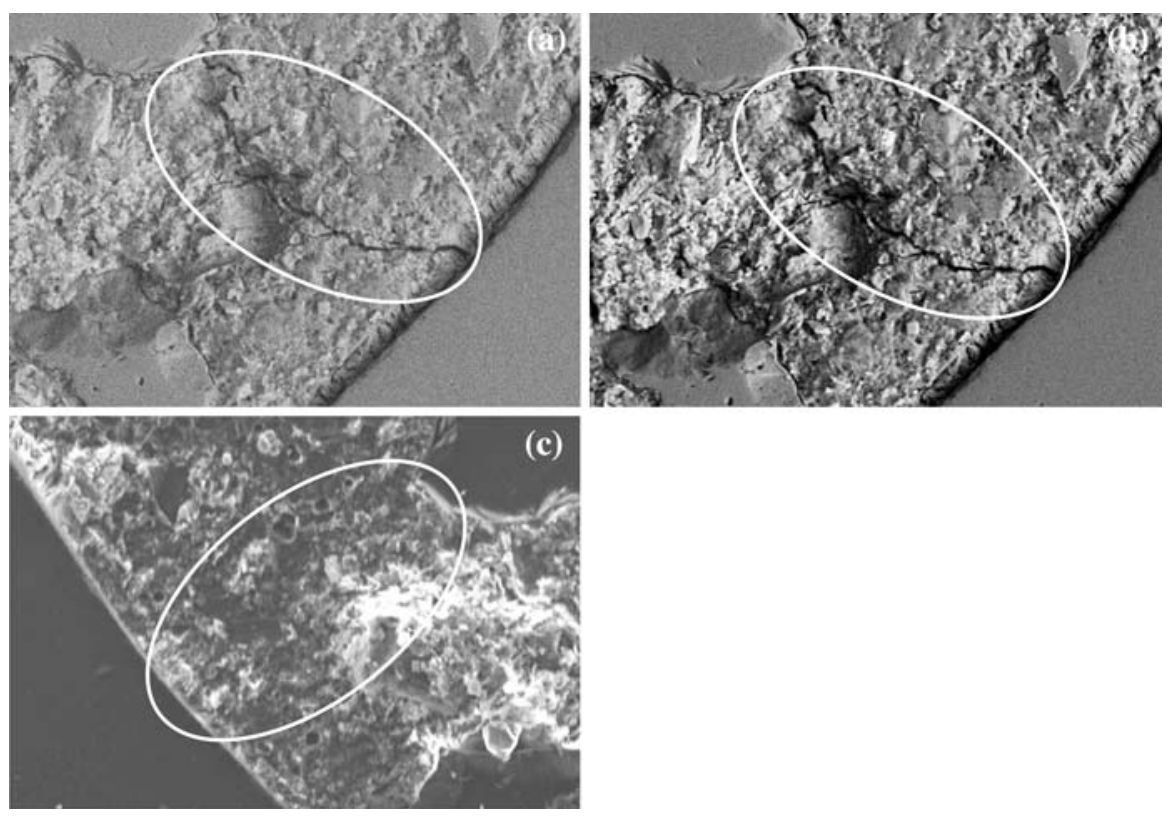

\section{c)}

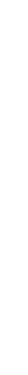

Fig. 4 BSE of the mortar A (high-vacuum mode): DEF at the paste/aggregate interface $(\mathbf{a}, \mathbf{b})$, and in cracks extending into the cement paste $(\mathbf{c})$. a 145 days, $400 \times$, b 200 days, $450 \times$, c 450 days, $400 \times$
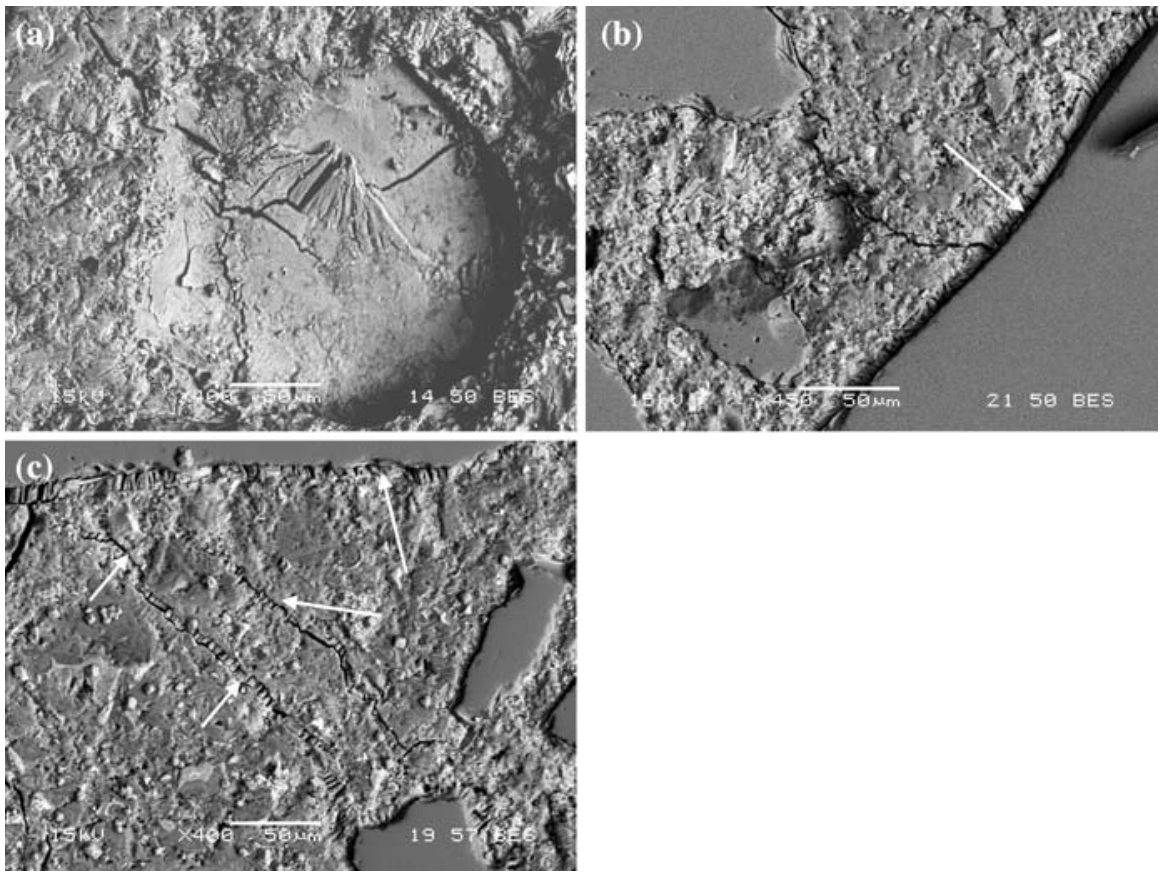

swelling, the observation of the sample did not make it possible to show up other traces of delayed ettringite in the paste. Yet, the microscopic images show that the phenomenon was beginning and that, for small expansions, secondary ettringite was starting to be located at the paste-aggregate interface. Moreover, observations of the replica do not show the presence of detectable microcracks. Figure $4 b$ and $c$ show that, starting from a certain expansion (about $0.1 \%$ ), delayed ettringite is easily observable at the paste-aggregate interface in the form of bands. At these levels of expansion, neither delayed ettringite nor microcracks were observable in cement paste. The empty cracks that can be seen on microscopic image $4 \mathrm{~b}$ are due to the preparation and observation of the sample, as shown in Fig. 3. For high levels of 
expansion ( $1.8 \%$ in the case of mortar A), cracks filled with ettringite are observable in the cement paste (Fig. 4c).

\subsection{Concrete B}

Figure 5 presents the length variations of concrete B. In this case, the evolution of the expansion is very different from that observed in the case of mortar A with sodium sulphate.

First, even though the swelling induced by the sulphate attack is considerable (greater than $0.1 \%$ ), the level of expansion reached is much lower than in the case of the mortar with sodium sulphate. The expansion is much faster in the case of the mortar, with a sigmoid-shaped curve of evolution, whereas, in the case of the concrete, the evolution of the expansion still remains linear after 1,200 days but swelling is not finished [28].

As for the mortar, the influence of the technical preparation and observation of the samples was studied in the same section of concrete $B$ at the age of 1,200 days ( $0.3 \%$ expansion).

Figure 6 shows SEM images of the same polished section of concrete B using the three techniques of observation (replicas, low-vacuum and high-vacuum).

The main observations made on mortar $\mathrm{A}$ are confirmed: empty microcracks are observable in lowvacuum and high-vacuum mode (Fig. 6a, b) while they are absent on the replica (Fig. 6c).

Finally, Fig. 7 presents BSE images of concrete B at different stages of expansion (300, 800 and 1,176 days).

The microscopic images of concrete B are very similar to those of mortar A. For low expansion levels (around $0.05 \%$ ), delayed ettringite is observable at

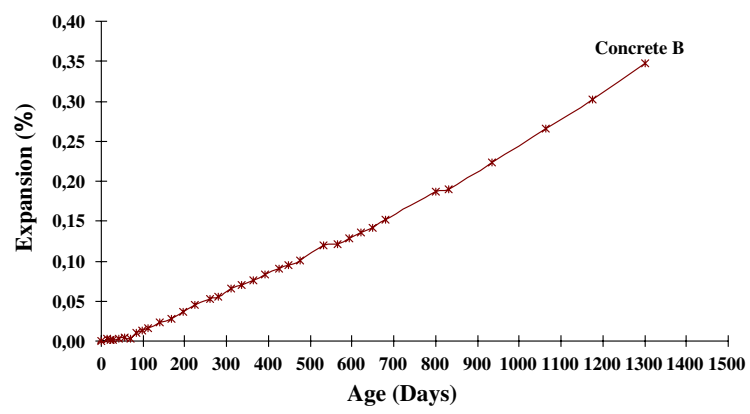

Fig. 5 Length variations of concrete B the paste-aggregate interface as was the case for mortar A (Fig. 7a). The evolution of the localization of the ettringite with the increase of the expansion is also similar to that observed in mortar A. When the level of expansion increases, delayed ettringite is again observed in the paste-aggregate interface in the form of bands (Fig. 7b). Then cracks filled with ettringite appear in the cement paste at high levels of expansion (Fig. 7c). As was the case for mortar A, the empty cracks that can be seen on Fig. 7c are due to the preparation and observation of the sample. This can be confirmed by examining the replica of the same area (Fig. 7d).

\section{Discussion}

\subsection{Influence of the observation technique}

The study of the influence of the observation technique was carried out using three different techniques: direct observation in low- and high-vacuum mode and the replica technique, which has the advantage of not damaging the material. The observations were made on samples of mortar and concrete affected by DEF. Although the evolutions of the expansion are very different between the mortar doped with sodium sulphate and the traditional concrete, the results obtained for the influence of the observation technique are identical for both types of materials.

The direct observations in low- and high-vacuum mode are still comparable and show the presence of empty cracks. The absence of these empty cracks on the images of the replicas taken immediately after polishing show that these cracks were necessarily formed during the preparation or observation of the SEM samples. They are therefore not due to DEF. Moreover, the same cracks are observed for different pressures and particularly for very low pressures (60 $\mathrm{Pa}$ in low-vacuum mode), which shows that the pressure does not seem to be the only factor responsible for this cracking.

From these results it can be concluded that direct observations, even in low-vacuum mode, are not suitable for following the evolution of the microcracking of specimens with DEF. For such studies, the replica technique is more appropriate. The results obtained in this work show that this technique, which was developed for the study of microcracking due to 
Fig. 6 BSE of concrete B in low- and high-vacuum mode $(\mathbf{a}, \mathbf{b})$ and SEI of the replica $(\mathbf{c}),(1,200$ days, $400 \times)$

Fig. 7 BSE of concrete B (high-vacuum mode): DEF at the paste/aggregate interface $(\mathbf{a}, \mathbf{b})$ and in cracks extending into the cement paste (c). SEI of the replica corresponding to the zone observed (d). a 300 days, $400 \times$, b 800 days, $600 \times$, c 1,176 days, $450 \times$ d 1,176 days, $450 \times$ (replica)
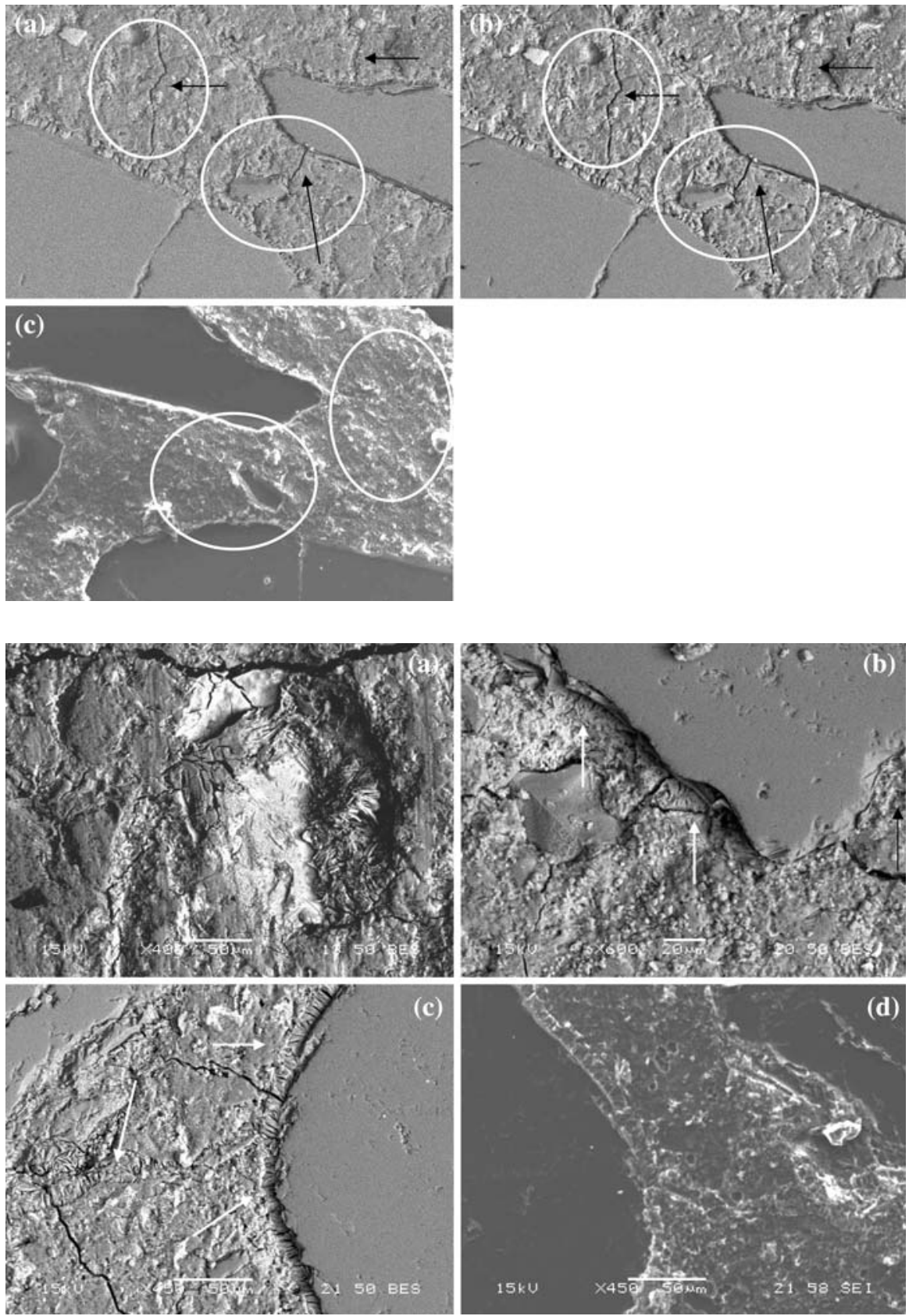

mechanical damage to concrete, is very well suited to following the microcracks associated with DEF. However, this technique does not provide microscopic images that are sufficiently clear to permit the morphology of the samples to be studied correctly and, in particular, to enable the ettringite to be localized. Thus, it would be interesting to combine the observations made using the replica technique (study of microcracking) with direct observations using the SEM (study of the morphology) to characterize this pathology efficiently on a microscopic scale.

\subsection{Observations of delayed ettringite during expansion}

The second important point of this article is related to the study of the evolution of ettringite precipitation during the expansion of DEF-affected specimens. 
The results obtained on the mortar with sodium sulphate and on the traditional concrete were found to be identical. It is interesting to compare these observations with the two main opposing theories on the mechanisms of expansion already mentioned.

In a review of DEF based on the work of many other researchers, Taylor et al. [2] propose the following expansion mechanism. Small crystals of ettringite start to form in the cement paste, which induces a global expansion of the material. As a result of this expansion, cracks appear within the cement paste and at the paste-aggregate interface. Then ettringite dissolves and recrystallizes in these cracks without causing swelling, which is of supplementary importance. Taylor et al. based their theory strongly on the results of analyses obtained using EDS, according to which the expansion is due to the precipitation of ettringite in the paste (more specifically in the outer $\mathrm{C}-\mathrm{S}-\mathrm{H}$ ). The observations presented in this article did not allow the presence of ettringite to be identified in the cement paste at the beginning of swelling. These two points are not contradictory because the scale of observation used is not exactly the same. However, according to the previous theory, the expansion of the cement paste first causes microcracks in the cement paste and at the paste-aggregate interface and it is only later that these cracks are filled with ettringite. The results of the present study do not support this theory about the phenomena observed and, above all, about the order of appearance of these phenomena. Indeed, the observations show that ettringite is initially observable at the pasteaggregate interface and this is the case for very low levels of expansion (Figs. 4a, 7a). When the levels of expansion increase, ettringite is always found in the interfacial transition zone (ITZ) in the form of bands and the presence of these rims of ettringite around the aggregate is more and more systematic (Figs. 4b, 7b). In contrast to what the previous theory proposed, there are no observable empty cracks in the cement paste other than those due to the technique of observation of the samples. Finally, for significant levels of expansion, cracks filled with ettringite appear in the cement paste (Figs. 4c, 7c). The microstructure of the final specimens with DEF is therefore similar to that described in the theory of Taylor (cracks filled with ettringite observable in the cement paste and at the paste-aggregate interface), but the order of appearance of the phenomena observed is very different.
The phenomena observed, and especially their order of appearance, are more in agreement with the second theory, known as the theory of the crystalline pressure, supported by Diamond [7]. According to this theory, the expansion of specimens affected by DEF is due to the growth of ettringite crystals in microcracks. The first location of precipitation of the ettringite is the paste-aggregate interface, which is in good agreement with the observations made in this article (Figs. 4a, 7a). The formation and accumulation of delayed ettringite at these interfaces (Figs. 4b, 7b) produce high pressures which are at the origin of the expansion of the specimens. Moreover, these pressures are released by the development of cracks in the cement paste. The ettringite can then form inside these new cracks and can participate in the global expansion of the material (Figs. 4c, 7c).

\section{Conclusions}

This article deals with the modifications of DEFaffected materials on a microscopic scale. For reasons of convenience, a part of the study was carried out on a mortar doped with sodium sulphate as this addition makes it possible to considerably accelerate and amplify the DEF, thus rendering its study easier. At the same time, a similar study was carried out on specimens of DEF-affected concrete that had been stored in the laboratory for more than 3 years. Although very different degrees of swelling were present, the microscopic observations made on the two types of materials were very similar.

Observations were carried out with the SEM using various techniques of preparation and observation of the samples. The results showed that the procedure used significantly influenced the observations and especially the microcracking in the specimens. In particular, direct observations of DEF-affected specimens generated empty microcracks in low- or highvacuum mode which were not ascribable to the pathology. For such studies, use of the replica technique is more appropriate because this technique does not damage the material and thus does not introduce artefacts in the observation of microcracks. The results obtained during this work show that this technique, developed for the study of microcracking due to mechanical damage to concrete, is very suitable for following the microcracks associated with DEF. 
The microscopic observations of the two types of materials at different stages of expansion lead to significant conclusions. First of all, the first visible traces of secondary ettringite are observable at the paste-aggregate interface, even for low levels of expansion. Moreover, for these levels of expansion, the SEM observations failed to find any trace of delayed ettringite in the paste or microcracks due to a possible expansion of the paste. When the level of expansion increases, increasing quantities of ettringite continue to appear around the aggregates in the form of easily recognizable bands. Cracks full of ettringite appear in the cement paste when swelling reaches some significant value. These observations were compared with the two classical theories existing on the mechanisms related to DEF. The results presented in this article seem to be rather in agreement with the theory of crystalline pressure.

\section{References}

1. Heinz D, Ludwig U (1985) Mechanism of subsequent ettringite formation in mortars and concrete after heat treatment. In: 8th international congress chemistry of cement, Rio de Janeiro, vol 5, pp 189-194

2. Taylor H-F-W, Famy C, Scrivener K-L (2001) Delayed ettringite formation. Cem Concr Res 31:683-693. doi: 10.1016/S0008-8846(01)00466-5

3. Barbarulo R (2002) Comportement des matériaux cimentaires: actions des sulfates et de la température. Ph.D. Thesis, Ecole Normale Supérieure de Cachan, Faculté des études supérieures de l'Université de Laval, September 2002, p 271

4. Glasser F-P (2002) The stability of ettringite. In: Workshop on internal sulfate attack and delayed ettringite formation, RILEM proceedings PRO 35

5. Collepardi M (2002) The influence of sulphate content in clinker or cement and curing temperature on DEF-related expansion of concrete. In: Workshop on internal sulfate attack and delayed ettringite formation, RILEM proceedings PRO 35

6. Lewis M-C, Scrivener K-L, Kelham S (1995) Heat curing and delayed ettringite formation. In: Materials research society symposium proceedings, vol 370, pp 67-76

7. Diamond S (1996) Delayed ettringite formation-processes and problems. Cem Concr Compos 18:205-215. doi:10.1016/0958-9465(96)00017-0

8. Escadeillas G, Aubert J-E, Segerer M, Prince W (2007) Some factors affecting delayed ettringite formation in heatcured mortars. Cem Concr Res 37:1445-1452. doi: 10.1016/j.cemconres.2007.07.004

9. Scherer W (2002) Factors affecting crystallisation pressure. In: Workshop on internal sulfate attack and delayed ettringite formation, RILEM proceedings PRO 35
10. Scrivener K-L, Guidoum A, Mathier V (2002) Role of cracks in delayed ettringite formation. In: Workshop on internal sulfate attack and delayed ettringite formation, RILEM proceedings PRO 35

11. Fu Y, Beaudoin J-J (1996) Thermal stability of ettringite formation in Portland cement systems. ACI Mater J 93:327-333

12. Damidot D, Glasser F-P (1992) Thermodynamic investigation of the $\mathrm{CaO}-\mathrm{Al}_{2} \mathrm{O}_{3}-\mathrm{CaSO}_{4}-\mathrm{H}_{2} \mathrm{O}$ system at $50^{\circ} \mathrm{C}$ and $85^{\circ} \mathrm{C}$. Cem Concr Res 22:1179-1191. doi:10.1016/00 08-8846(92)90047-Y

13. Shimada Y, Francis Young J (2004) Thermal stability of ettringite in alkaline solutions at $80^{\circ} \mathrm{C}$. Cem Concr Res 34:2261-2268. doi:10.1016/j.cemconres.2004.04.008

14. Skalny J (2002) Internal sulfate attack-points of agreement and disagreement. In: Workshop on internal sulfate attack and delayed ettringite formation, RILEM proceedings PRO 35

15. Odler I, Gasser M (1988) Mechanism of sulfate expansion in hydrated Portland cement. J Am Ceram Soc 71(11): 1015-1020. doi:10.1111/j.1151-2916.1988.tb07573.x

16. Famy C (1999) Expansion of heat-cured mortars. PhD Thesis, Imperial College University of London, September 1999, p 256

17. Scherer W-G (2002) Factors affecting crystallization pressure. In: Workshop on internal sulfate attack and delayed ettringite formation, RILEM proceedings PRO 35

18. Scrivener K-L, Skalny J (2002) Conclusions of the international RILEM TC 186-ISA workshop on internal sulfate attack and delayed ettringite formation. In: Workshop on internal sulfate attack and delayed ettringite formation, RILEM proceedings PRO 35

19. Yang R, Lawrence C-D, Lynsale C-J, Sharp J-H (1999) Delayed ettringite formation in heat-cured Portland cement mortar. Cem Concr Res 29:17-25. doi:10.1016/S00088846(98)00168-9

20. Fu Y, Beaudoin JJ (1996) Mechanisms of delayed ettringite formation in Portland cement systems. ACI Mater J 93(4):327-333

21. McDonald D (1998) Delayed ettringite formation and heat curing -implications of the work of Kelham. Cem Concr Res 28(12):1827-1830. doi:10.1016/S0008-8846(98)00152-5

22. Grattan-Bellew PE (2000) A discussion of the paper "delayed ettringite formation in heat-cured Portland cement mortars" by R. Yang, C.D. Lawrence, C.J. Lynsdale. J.H. Sharp. Cem Conc Res 30:665-666. doi: 10.1016/ S0008-8846(99)00235-5

23. Fu Y, Ding J, Beaudoin JJ (1997) Expansion of Portland cement mortar due to internal sulfate attack. Cem Concr Res 27(9):1299-1306. doi:10.1016/S0008-8846(97)00133-6

24. Grattan-Bellew PE, Beaudoin JJ, Vallée V-G (1998) Effect of aggregate particle size and composition on expansion of mortar bars due to delayed ettringite formation. Cem Concr Res 28(8):1147-1156. doi:10.1016/S0008-8846(98)00084-2

25. Yang R, Lawrence CD, Sharp JH (1999) Effect of type of aggregate on delayed ettringite formation. Adv Cem Res 11(3):119-132

26. Ollivier JP (1985) A non destructive procedure to observe the microcracks of concrete by scanning electron microscopy. Cem Concr Res 15:1055-1060. doi:10.1016/0008-8846 (85)90097-3 
27. Ringot E, Escadeillas G, Ollivier JP (1988) Investigation of interfacial cracking in hydraulic concrete by a replica procedure. COMP'88, phase interaction in composite materials, Patras
28. Brunetaud X, Linder R, Divet L, Duragrin D, Damidot D (2007) Effect of curing conditions and concrete mix design on the expansion generated by delayed ettringite formation. Mater Struct 40:567-578. doi:10.1617/s11527-006-9163-3 